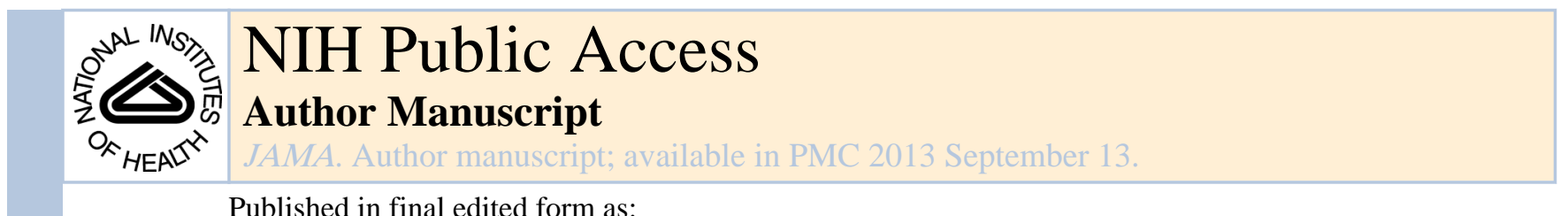

JAMA. 2012 November 7; 308(17): 1768-1774. doi:10.1001/jama.2012.14306.

\title{
Association of Race and Sex With Risk of Incident Acute Coronary Heart Disease Events
}

\author{
Monika M. Safford, MD ${ }^{1}$, Todd M. Brown, MD, MSPH ${ }^{1}$, Paul Muntner, $\mathrm{PhD}^{4}$, Raegan W. \\ Durant, MD, MPH ${ }^{1}$, Stephen Glasser, MD $^{1}$, Jewell Halanych, MD, MSc ${ }^{1}$, James M. Shikany, \\ $\mathrm{DrPH}^{1}$, Ronald Prineas, MD, PhD ${ }^{2}$, Tandaw Samdarshi, MD ${ }^{3}$, Vera Bittner, MD, MSPH ${ }^{1}$, Cora \\ E. Lewis, MD, MSPH ${ }^{1}$, Christopher Gamboa, MPH ${ }^{4}$, Mary Cushman, MD ${ }^{5}$, Virginia Howard, \\ $\mathrm{PhD}^{4}$, George Howard, DrPH ${ }^{4}$, and For the REGARDS Investigators \\ Monika M. Safford: msafford@uab.edu; Todd M. Brown: tmbrown@uab.edu; Paul Muntner: pmuntner@ms.soph.uab.edu; \\ Raegan W. Durant: rdurant@uab.edu; Stephen Glasser: sglasser@uab.edu; Jewell Halanych: jhalanych@uab.edu; \\ James M. Shikany: jshikany@uab.edu; Ronald Prineas: rprineas@wfubmc.edu; Tandaw Samdarshi: \\ tsamdarshi@medicine.umsmed.edu; Vera Bittner: vbittner@uab.edu; Cora E. Lewis: clewis@uab.edu; Christopher \\ Gamboa: gamboa-s@ms.soph.uab.edu; Mary Cushman: mary.cushman@uvm.edu; Virginia Howard: vjhoward@uab.edu; \\ George Howard: ghoward@uab.edu \\ ${ }^{1}$ University of Alabama School of Medicine \\ 2Wake Forest University \\ 3 University of Mississippi \\ ${ }^{4}$ University of Alabama at Birmingham School of Public Health \\ 5 University of Vermont School of Medicine
}

\begin{abstract}
CONTEXT-It is unknown whether long-standing disparities in incidence of coronary heart disease (CHD) among US blacks and whites persist.
\end{abstract}

\footnotetext{
Corresponding Author: Monika M. Safford, MD, University of Alabama School of Medicine, $171711^{\text {th }}$ Avenue South, MT643, Birmingham, AL 35294-4410, Telephone: 205-934-6883 Fax: 205-975-6753, msafford@uab.edu.

Author Affiliations: University of Alabama at Birmingham School of Medicine (Monika M. Safford, MD; Todd M. Brown, MD, MSPH; Raegan W. Durant, MD, MPH; Stephen Glasser, MD; Jewell Halanych, MD, MSc; James M. Shikany, DrPH; Vera Bittner, MD, MSPH; Cora E. Lewis, MD, MSPH); Wake Forest University (Ronald Prineas, MD, PhD); University of Mississippi (Tandaw Samdarshi, MD); University of Alabama at Birmingham School of Public Health (Paul Muntner, PhD; Christopher Gamboa, MPH; Virginia Howard, PhD; George Howard, DrPH); University of Vermont School of Medicine (Mary Cushman, MD).

Author Contributions: Dr Safford had full access to all of the data in the study and takes responsibility for the integrity of the data and the accuracy of the data analysis.

Study concept and design: Safford, Muntner, Durant, Lewis, Cushman, V. Howard. Acquisition of data: Safford, Prineas, Samdarshi, Lewis, V. Howard, G. Howard.

Analysis and interpretation of data: Safford, Brown, Muntner, Durant, Glasser, Halanych, Shikany, Bittner, Gamboa, Cushman, G. Howard.

Drafting of the manuscript: Safford, Gamboa.

Critical revision of the manuscript for important intellectual content: Safford, Brown, Muntner, Durant, Glasser, Halanych, Shikany, Prineas, Samdarshi, Bittner, Lewis, Cushman, V. Howard, G. Howard.

Statistical analysis: Muntner, Samdarshi, Gamboa.

Obtained funding: Safford, Prineas, G. Howard.

Administrative, technical, or material support: Safford, Brown, Durant, Lewis, Cushman, V. Howard, G. Howard.

Study supervision: Safford, Muntner, Glasser, Halanych, Cushman, V. Howard.

Conflict of Interest Disclosures: The authors have completed and submitted the ICMJE Form for Disclosure of Potential Conflicts of Interest. Dr Brown reported receiving grants from Amgen Pharmaceuticals not related to this article. Dr Muntner reported serving on an Amgen advisory board in 2011; serving as a consultant to Amgen; and receiving grants from Amgen. Dr Lewis reported receiving a grant from NovoNordisk for an obesity study. No other authors reported any disclosures.
}

Disclaimer: The content is solely the responsibility of the authors and does not necessarily represent the official views of the National Institute of Neurological Disorders and Stroke or the National Institutes of Health. 
OBJECTIVE-To examine incident CHD by black and white race and by sex.

DESIGN, SETTING, AND PARTICIPANTS-Prospective cohort study of 24443 participants without CHD at baseline from the Reasons for Geographic and Racial Differences in Stroke (REGARDS) cohort, who resided in the continental United States and were enrolled between 2003 and 2007 with follow-up through December 31, 2009.

MAIN OUTCOME MEASURE-Expert-adjudicated total (fatal and nonfatal) CHD, fatal CHD, and nonfatal CHD (definite or probable myocardial infarction [MI]; very small non-ST-elevation MI [NSTEMI] had peak troponin level $<0.5 \mu \mathrm{g} / \mathrm{L}$ ).

RESULTS-Over a mean (SD) of 4.2 (1.5) years of follow-up, 659 incident CHD events occurred (153 in black men, 138 in black women, 254 in white men, and 114 in white women). Among men, the age-standardized incidence rate per 1000 person-years for total CHD was 9.0 (95\% CI, 7.5-10.8) for blacks vs 8.1 (95\% CI, 6.9-9.4) for whites; fatal CHD: 4.0 (95\% CI, 2.95.3) vs 1.9 (95\% CI, 1.4-2.6), respectively; and nonfatal CHD: 4.9 (95\% CI, 3.8-6.2) vs 6.2 (95\% CI, 5.2-7.4). Among women, the age-standardized incidence rate per 1000 person-years for total CHD was 5.0 (95\% CI, 4.2-6.1) for blacks vs 3.4 (95\% CI, 2.8-4.2) for whites; fatal CHD: 2.0 (95\% CI, 1.5-2.7) vs 1.0 (95\% CI, 0.7-1.5), respectively; and nonfatal CHD: 2.8 (95\% CI, 2.23.7 ) vs 2.2 (95\% CI, 1.7-2.9). Age- and region-adjusted hazard ratios for fatal CHD among blacks vs whites was near 2.0 for both men and women and became statistically nonsignificant after multivariable adjustment. The multivariable-adjusted hazard ratio for incident nonfatal CHD for blacks vs whites was 0.68 (95\% CI, 0.51-0.91) for men and 0.81 (95\% CI, 0.58-1.15) for women. Of the 444 nonfatal CHD events, 139 participants (31.3\%) had very small NSTEMIs.

CONCLUSIONS-The higher risk of fatal CHD among blacks compared with whites was associated with cardiovascular disease risk factor burden. These relationships may differ by sex.

\section{Keywords}

coronary heart disease; epidemiology; racial disparities; disease incidence; cohort study

\section{Introduction}

Although mortality rates for acute myocardial infarction (MI) and coronary heart disease (CHD) have declined in the United States since the $1970 \mathrm{~s},{ }^{1-4}$ both death certificate data and evidence from 4 US communities suggest a steeper decline in acute CHD mortality between 2000 and 2008 for whites than for blacks, widening a long-standing disparity. ${ }^{5-6}$ Furthermore, data from Kaiser Permanente suggested that hospitalizations for MI decreased between 2002 and $2007,{ }^{7}$ but more so for whites than for blacks. Neither death certificate data nor health plan data permit examination of incident events. ${ }^{5,8-10}$

Two other major secular trends may influence contemporary estimates of incident CHD. First, statins have come into wide use over the past 10 years, ${ }^{11}$ lowering incidence rates. Second, cardiac troponin assays have become increasingly sensitive and very small amounts of myocardial necrosis are now routinely detected. Even very small non-ST-elevation MIs (NSTEMIs), with peak troponin level of less than $0.5 \mu \mathrm{g} / \mathrm{L}$, may confer similar long-term risks as larger MIs. ${ }^{12-14}$ However, very small NSTEMIs have only recently been included in studies of MI event rates, resulting in higher reported MI incidence rates. The overall effect of these secular trends on estimates of CHD incidence and racial disparities is unclear.

We analyzed data from the national Reasons for Geographic and Racial Differences in Stroke (REGARDS) cohort with 3 objectives: (1) to examine racial and sex differences in incident total CHD, fatal CHD, and nonfatal CHD across race-sex groups, (2) to examine 
whether risk factors were associated with observed race-sex risk differences, and (3) to examine race-sex differences in participants with very small NSTEMIs.

\section{Methods}

\section{REGARDS Cohort Study Procedures}

REGARDS is a prospective cohort study of 30239 individuals examining regional and racial influences on stroke mortality. Details are described elsewhere ${ }^{15-16}$; briefly, participants were enrolled between 2003 and 2007 using commercially available lists and a combination of mail and telephone contacts to recruit English-speaking, communitydwelling adults aged 45 years or older, who were living in the continental United States. Race and sex were balanced by design, with oversampling from the Southeastern United States; the final cohort included 58\% of participants who were women and $42 \%$ of participants who had black race. Race was self-reported. Baseline data collection included computer-assisted telephone surveys assessing medical history and health status. In-home examinations by trained health care professionals followed standardized, quality-controlled protocols to collect fasting blood and urine samples; electrocardiograms; blood pressure, height, and weight measurements; and medication use by pill bottle review. Blood and urine samples were centrally analyzed at the University of Vermont. Electrocardiograms were centrally analyzed at Wake Forest University.

Living participants or their proxies were followed up every 6 months by telephone with retrieval of medical records for reported hospitalizations. Deaths were detected by report of next of kin or through online sources (eg, Social Security Death Index) and the National Death Index. Proxies or next of kin were interviewed about the circumstances surrounding death, including the presence of chest pain. Death certificates and autopsy reports also were obtained to adjudicate cause of death.

For this study, individuals with prevalent CHD (self-report of MI or coronary revascularization procedure at baseline or evidence of prior MI on the baseline electrocardiogram) were excluded. Events through December 31, 2009, were included in this analysis. At that time, 9.5\% were lost to follow-up. The study protocol was reviewed and approved by the institutional review boards at the participating institutions and all participants provided informed consent.

\section{Acute CHD Events}

The CHD events were adjudicated by a team of experts who used published guidelines. ${ }^{17-18}$ For MI, medical records were examined for the presence of signs or symptoms suggestive of ischemia; a rising and/or falling pattern in cardiac troponin level or creatine phosphokinaseMB level over 6 or more hours with a peak level greater than twice the upper limit of normal (diagnostic cardiac enzymes); and electrocardiogram changes consistent with ischemia or MI, guided by the Minnesota code and classified as evolving diagnostic, positive, nonspecific, or not consistent with ischemia. ${ }^{19-20}$ Definite MIs were those with diagnostic enzymes or electrocardiogram. Probable MIs were those with elevated but not diagnostic (ie, equivocal) enzymes with a positive but not diagnostic electrocardiogram; or, if enzymes were missing, with a positive electrocardiogram in the presence of ischemic signs or symptoms. Only definite or probable MIs were included as events in this study. The highest and lowest levels of troponin and upper limits of normal for the hospital's assay also were recorded. Myocardial infarction that was adjudicated to have been caused by an invasive procedure was classified as procedure-related.

Because there is no widely accepted approach to defining very small NSTEMI, we examined publicly available upper limits of normal for commercially available troponin 
assays $^{21}$ and conservatively used $0.5 \mu \mathrm{g} / \mathrm{L}$ as the threshold of peak troponin to define very small NSTEMI, which is a level above twice the upper limit of all but 1 assay. Other MIs, including the 9 without troponin level available, were considered typical MIs. Elective and urgent coronary revascularization procedures were not included in the main analysis because their use differs by race..$^{22-30}$

For fatal events, the medical history, hospital records, interviews with next of kin or proxies, and death certificate or National Death Index data were reviewed to adjudicate the cause of death, with definite or probable CHD death used in the analysis (an expanded definition appears in the eAppendix). ${ }^{17}$

Cases were assigned to 2 adjudicators and disagreements were adjudicated by committee. The test for agreement between adjudicators yielded a $\mathrm{K}$ level greater than 0.80 for the presence of definite or probable MI or definite or probable acute CHD death.

The 3 main end points examined were a composite of fatal (definite or probable CHD death) or nonfatal CHD (definite or probable MI), and fatal and nonfatal CHD events, separately. Within nonfatal CHD events, we also examined very small NSTEMI and typical MI separately.

\section{Covariates}

Age, race, sex, income, education, and smoking status were self-reported. Annual income was dichotomized at less than $\$ 20000$ and education was dichotomized at less than a high school diploma. Smokers were defined as having smoked at least 100 cigarettes in their lifetime and smoking now, even if just occasionally. Use of antihypertensive and statin medications was based on self-report and pill bottle review.

The biometrics used in this analysis included body mass index (BMI; calculated as weight in kilograms divided by height in meters squared) and blood pressure. Participants had their height and weight measured using a standardized protocol during the in-home visit. Body mass index was modeled as a continuous measure. Blood pressure was obtained using an aneroid sphygmomanometer after a seated rest of 5 minutes with both feet on the floor. ${ }^{16}$ Two measures were obtained following a standardized protocol and averaged. Systolic blood pressure was modeled as a continuous variable.

Blood and urine markers included levels of total cholesterol, high-density lipoprotein (HDL) cholesterol, fasting glucose, high-sensitivity $\mathrm{C}$-reactive protein (CRP), serum creatinine, and urinary albumin and creatinine from a spot urine specimen. Total and HDL cholesterol levels were modeled as continuous variables. Diabetes was classified as present if fasting glucose level was $126 \mathrm{mg} / \mathrm{dL}$ or greater (nonfasting glucose level: $\geq 200 \mathrm{mg} / \mathrm{dL} ; \mathrm{n}=229$ ) or if patient reported taking diabetes medications. High-sensitivity CRP was log-transformed and modeled as a continuous variable. Estimated glomerular filtration rate (GFR) was calculated using the Chronic Kidney Disease Epidemiology Collaboration equation. ${ }^{31}$ Urinary albumin and creatinine levels were used to define the ratio of albumin to creatinine.

\section{Analysis}

Age-standardized incidence rates per 1000 person-years were calculated for each race and sex group for each end point. Sex-stratified Cox proportional hazards models were constructed to estimate the hazard ratios (HRs) for blacks compared with whites for incident events for the 3 end points (total CHD, fatal CHD, and nonfatal CHD). The assumptions of proportionality were met and there were no time-dependent variables. Individuals were censored at the time of their event, death, or the end of follow-up. Models were constructed incrementally to examine changes in HR as covariates were added. Model 1 adjusted for age 
and region (stroke belt, stroke buckle, or other parts of the continental United States because the REGARDS study oversampled residents of the stroke belt and stroke buckle). Model 2 added income and education to model 1 covariates. Model 3 added Framingham risk factors (levels of total and HDL cholesterol, smoking status, systolic blood pressure, and diabetes status) and use of statin or antihypertensive medication to model 2 covariates. Model 4 added BMI, estimated GFR, and log-transformed ratio of albumin to creatinine, and highsensitivity CRP to model 3 covariates. Missing covariates were imputed using chained equations with 5 data sets. ${ }^{32-33}$

We calculated the age-standardized incidence of very small NSTEMI and typical MI per 1000 person-years for each race and sex group. The HRs for blacks compared with whites for typical and very small NSTEMI were estimated from sex-stratified Cox proportional hazards models with identical incremental adjustment as those described above for the main analysis.

Sensitivity analyses examined the effect of including elective and urgent percutaneous coronary revascularization procedures and coronary artery bypass graft surgery in the analysis as incident events. After including these procedures, the age-standardized rates for total incident CHD, fatal CHD, and nonfatal CHD and Cox proportional hazard models (as described above) were calculated for each race and sex group. Because blacks have a shorter life expectancy than whites, we also examined whether all-cause mortality among blacks was a competing risk for nonfatal CHD by entering all-cause mortality as a competing risk to the fully adjusted models. Also, we examined the role of MIs complicating coronary interventions and other surgical procedures for the end points. Statistical significance for all analyses was a $P$ value of less than .05 . Analyses were conducted using SAS version 9.2 (SAS Institute Inc) and Stata version 11 (StataCorp).

\section{Results}

\section{Sample Characteristics}

After excluding 5314 individuals with baseline CHD and 426 without follow-up, the study sample included 24443 participants (Table 1). Blacks and whites had a similar mean age, but blacks had less education and a lower income level. Smoking, diabetes, and reduced estimated GFR were more prevalent and systolic blood pressure, BMI, and level of highsensitivity CRP were higher among blacks than whites.

\section{Incidence Rates}

The mean (SD) follow-up time was 4.2 (1.5) years. The 659 total incident CHD events through December 31, 2009, included 153 events in black men, 254 in white men, 138 in black women, and 114 in white women (Table 2). Although the incidence rate per 1000 person-years of total CHD was similar among black men (9.0; 95\% CI, 7.5-10.8) and white men (8.1; 95\% CI, 6.9-9.4), black men had higher incidence of fatal CHD (4.0 [95\% CI, 2.9-5.3] vs 1.9 [95\% CI, 1.4-2.6] for white men) and lower incidence of nonfatal CHD (4.9 [95\% CI, 3.8-6.2] vs 6.2 [95\% CI, 5.2-7.4] for white men; Figure). Women had lower incidence rates per 1000 person-years than men within each racial group. However, black women had higher incidence rates per 1000 person-years for total CHD (5.0 [95\% CI, 4.26.1] vs 3.4 [95\% CI, 2.8-4.2] for white women), for fatal CHD (2.0 [95\% CI, 1.5-2.7] vs 1.0 [95\% CI, 0.7-1.5] for white women), and for nonfatal CHD (2.8 [95\% CI, 2.2-3.7] vs 2.2 [95\% CI, 1.7-2.9] for white women; Figure). 


\section{Risks for CHD}

For total CHD, the age- and region-adjusted HR for black men compared with white men was 1.15 (95\% CI, 0.94-1.41) (model 1) and in the fully adjusted model it was 0.87 (95\% CI, 0.69-1.08; model 4) (Table 3). Among women, the age- and region-adjusted HR for total CHD for blacks vs whites was 1.48 (95\% CI, 1.15-1.90) and in the fully adjusted model it was 0.90 (95\% CI, 0.68-1.20).

For fatal CHD, the age- and region-adjusted HR for black men compared with white men was 2.18 (95\% CI, 1.55-3.06) and in the fully adjusted model it was 1.34 (95\% CI, 0.911.96). Among women, the age- and region-adjusted HR for fatal CHD for blacks vs whites was 1.93 (95\% CI, 1.23-3.03) and in the fully adjusted model it was 1.14 (95\% CI, 0.691.99) (Table 3).

For nonfatal CHD, the age- and region-adjusted HR for black men compared with white men was 0.81 (95\% CI, 0.63-1.06) and in the fully adjusted model it was 0.68 (95\% CI, 0.51-0.91). Among women, the age- and region-adjusted HR for nonfatal CHD for blacks vs whites was 1.31 (95\% CI, 0.97-1.77) and in the fully adjusted model it was 0.81 (95\% CI, $0.58-1.15)$ (Table 3).

\section{Role of Very Small NSTEMI}

Very small NSTEMI comprised $31.3 \%$ of nonfatal CHD events; there were $33(40.2 \%)$ among black men, 47 (24.6\%) among white men, 35 (39.8\%) among black women, and 24 (28.9\%) among white women (Table 2). Incidence rates for typical MI were lower for black men than for white men, but rates for very small NSTEMI were similar (eFigure 1). In contrast, incidence rates for typical MI were similar for black women and white women, but incidence rates for very small NSTEMI were higher for black women than for white women.

The HRs for typical MI for blacks vs whites were similar to the overall nonfatal CHD results for both men and women (Table 4). The HR for very small NSTEMI was not statistically different for black men vs white men, but black women had a higher age-adjusted HR for very small NSTEMI vs white women, which became nonsignificant with full adjustment.

\section{Sensitivity Analyses}

Including coronary revascularization procedures substantially and disproportionately increased the age-standardized incidence rates for whites vs blacks. For white men, total CHD increased by $69.3 \%$ and nonfatal CHD increased by $93.7 \%$; for white women, total CHD increased by $63.2 \%$ and nonfatal CHD increased by $86.7 \%$. For black men, total CHD increased by $21.6 \%$ and nonfatal CHD increased by $42.7 \%$; for black women, total CHD increased by $34.1 \%$ and nonfatal CHD increased by $54.5 \%$. Effects on fatal CHD were trivial (eTable 1 and eFigure 2). For men, the HRs for blacks compared with whites for incident total and nonfatal CHD were lower than in the model without revascularizations, but there were minimal changes in the HRs for incident fatal CHD comparing black men with white men (eTable 2). For black women compared with white women, higher HRs for total CHD became significantly lower in the fully adjusted models; multivariable-adjusted HRs for nonfatal CHD also were significantly lower. Higher HRs for fatal CHD became nonsignificant with multivariable adjustment (eTable 2).

Accounting for the competing risk of all-cause mortality among blacks had little effect on the risks for nonfatal CHD (adjusted HRs comparing blacks with whites: 0.59 [95\% CI, $0.46-0.78$ ] for men and 0.87 [95\% CI, 0.64-1.18] for women without revascularizations; adjusted HRs comparing blacks with whites: 0.44 [95\% CI, 0.36-0.55] for men and 0.72 [95\% CI, 0.56-0.91] for women with revascularizations). There were 10 procedure-related 
MIs among black men and 23 among white men; the results including procedure-related MIs were almost identical to those that did not include these events.

\section{Comment}

In the REGARDS study, black men and black women had twice the age-standardized rate of fatal incident CHD compared with white men and white women. This increased risk was associated with racial differences in CHD risk factors, which were more prevalent among black men and women compared with white men and women. A marked sex difference was present for nonfatal acute CHD: black men had a lower risk of presenting with incident nonfatal acute MI than white men, but black women had a higher risk than white women. The low risk in black men remained present in the fully adjusted models, but the excess risk observed among black women was entirely attenuated after accounting for their higher cardiovascular disease risk factor burden. The high risk of presenting with death as the first manifestation of CHD among black men and women, which is associated with excess burden of cardiovascular disease risk factors, is similar to past reports ${ }^{4-7}$ and demonstrates little evidence of progress toward eliminating this disparity.

The incidence rates we observed were consistent with other reports of continued downward trends in MI and acute CHD mortality. There are relatively few biracial cohorts that provide incidence data in the United States. Incidence rates for CHD from the Atherosclerosis Risk in Communities (ARIC) study were substantially higher per 1000 person-years in the 1990s than in our study (10.6 for black men, 12.5 for white men, 5.1 for black women, and 4.0 for white women). ${ }^{34}$ Of note, coronary revascularizations were included as CHD events in that report. The use of these procedures has increased dramatically since that time, albeit with some recent decreases, ${ }^{22}$ and we observed lower revascularization use among black vs white REGARDS participants. More recently, the ARIC surveillance study reported declines in CHD death without history of MI as well as first MI from 1987 through 2008, revealing larger declines for whites than for blacks, with the lowest decline found in black men and an increase in first MI among black men. ${ }^{5}$ These results support the continued disparities in CHD we observed.

The racial and sex differences in fatal vs nonfatal acute CHD incidence rates that we observed are, to our knowledge, new. In the ARIC study, the incidence of overall CHD was similar for black and white men and for black and white women, but nonfatal and fatal events were not reported separately. ${ }^{34}$ A recent analysis of pooled ARIC and Cardiovascular Health Study data compared risks of sudden cardiac death (SCD) and non-SCD CHD (nonfatal CHD, including revascularization procedures, and fatal CHD judged not to be SCD) over 14 years ending in $2002 .{ }^{35}$ This study reported a HR of 1.81 (95\% CI, 1.31-2.49) for SCD for blacks compared with whites and a HR of 0.76 (95\% CI, 0.67-0.86) for nonSCD. While these categories are not directly comparable with ours, the results are generally concordant. Our more recent results, taken together with prior studies, suggest there has been disappointingly little progress in lowering the excess risk of death at first clinical presentation of acute CHD among blacks.

To our knowledge, previous reports have not found the lower risk of incident nonfatal CHD among black men that we described. The additional analyses we conducted did not support that all-cause mortality was a competing risk, or that procedure-related MI, which potentially could have inflated nonfatal CHD in white men, contributed substantially. The low risk was seen only for typical MIs but not very small NSTEMIs. Additional studies are needed to confirm these findings. 
The role of very small NSTEMI in the incidence of acute CHD is an emerging phenomenon. Numerous reports confirm the long-term risks associated with very small NSTEMIs, and experts including the European Society of Cardiology, the American College of Cardiology Federation, the American Heart Association, and the World Heart Federation recommend classifying such events as MIs. ${ }^{14,18,36-40}$ The large proportion of very small NSTEMIs suggests that comparisons of contemporary with past incidence rates will be complicated, especially for studies of racial disparities if our findings across race and sex groups are confirmed in other studies. In addition, the optimal threshold for defining very small NSTEMI is not clear; past reports that included estimates of the incidence of very small NSTEMI relative to typical MIs used varying definitions of this entity. ${ }^{14,38-39,41} \mathrm{We}$ selected a conservative threshold but other thresholds may be reasonable, and consensus on how to define very small NSTEMI across epidemiological studies may be warranted, along with consensus on how to handle very small NSTEMI for comparisons with past studies.

Limitations of this study include its observational design and attendant cautions about drawing causal inferences. The REGARDS cohort was not designed as a surveillance study; thus, we likely underestimated incidence for nonfatal CHD events but not for fatal CHD events, which have more complete ascertainment. Although the REGARDS cohort has wide reach, participants in any research study may differ from the general population, affecting generalizability. Some of our covariates were self-reported, which carries limitations. Future analyses will permit more in-depth exploration of very small NSTEMIs.

Strengths of this study include its national scope and unique in-home data collection, facilitating participation from residents of geographic areas beyond driving distance of large research institutions. The large number of geographically dispersed black and white participants is another notable strength, as is the contemporaneous nature of the cohort, with ongoing follow-up and rigorous adjudication of events using published guidelines, including conducting interviews with next of kin.

\section{Conclusions}

Similar incidence rates of total CHD among men obscured marked racial differences in fatal and nonfatal CHD. Fatal CHD risk was higher among black men and associated with known risk factors, but nonfatal CHD risk was lower with and without risk factor adjustment. In contrast, black women had higher rates of total, fatal, and nonfatal CHD, with higher risks attenuated by known risk factors. Excess risk factor burden among black men and women continues to be a major public health challenge, along with their high risk for death as the presentation of CHD. Increased emphasis on optimizing well-established CHD risk factors among blacks could potentially reduce these disparities.

\section{Supplementary Material}

Refer to Web version on PubMed Central for supplementary material.

\section{Acknowledgments}

Funding/Support: This research project was supported by grant R01 HL080477 from the National Heart, Lung, and Blood Institute (Dr Safford); grant KL2 RR025776-04 from the National Center for Research Resources (Dr Brown); and cooperative agreement U01 NS041588 from the National Institute of Neurological Disorders and Stroke, National Institutes of Health, Department of Health and Human Services (Dr G Howard). Additional funding was provided by an investigator-initiated grant-in-aid from Amgen Corporation (Dr Safford).

Role of the Sponsors: Representatives of the funding agencies have been involved in the review of the manuscript but not directly involved in the collection, management, analysis or interpretation of the data. Amgen did not have 
any role in the design and conduct of the study; in the collection, management, data analysis, and interpretation of the data; or in the preparation or approval of the manuscript.

\section{REFERENCES}

1. Hozawa A, Folsom AR, Sharrett AR, Chambless LE. Absolute and attributable risks of cardiovascular disease incidence in relation to optimal and borderline risk factors: comparison of African American with white subjects-Atherosclerosis Risk in Communities Study. Arch Intern Med. 2007; 167(6):573-579. [PubMed: 17389288]

2. Mensah GA. Eliminating disparities in cardiovascular health: six strategic imperatives and a framework for action. Circulation. 2005; 111(10):1332-1336. [PubMed: 15769777]

3. Mensah GA, Mokdad AH, Ford ES, Greenlund KJ, Croft JB. State of disparities in cardiovascular health in the United States. Circulation. 2005; 111(10):1233-1241. [PubMed: 15769763]

4. Roger VL, Go AS, Lloyd-Jones DM, et al. American Heart Association Statistics Committee and Stroke Statistics Subcommittee. Heart disease and stroke statistics-2012 update: a report from the American Heart Association. Circulation. 2012; 125(1):e2-e220. [PubMed: 22179539]

5. Rosamond WD, Chambless LE, Heiss G, et al. Twenty-two-year trends in incidence of myocardial infarction, coronary heart disease mortality, and case fatality in 4 US communities, 1987-2008. Circulation. 2012; 125(15):1848-1857. [PubMed: 22420957]

6. Centers for Disease Control and Prevention. [Accessed April 27, 2011] CDC wonder compressed mortality file. 2011. http://wonder.cdc.gov/mortsql.html

7. Yeh RW, Sidney S, Chandra M, Sorel M, Selby JV, Go AS. Population trends in the incidence and outcomes of acute myocardial infarction. N Engl J Med. 2010; 362(23):2155-2165. [PubMed: 20558366]

8. Zheng ZJ, Croft JB, Giles WH, Mensah GA. Sudden cardiac death in the United States, 1989 to 1998. Circulation. 2001; 104(18):2158-2163. [PubMed: 11684624]

9. Lloyd-Jones DM, Martin DO, Larson MG, Levy D. Accuracy of death certificates for coding coronary heart disease as the cause of death. Ann Intern Med. 1998; 129(12):1020-1026. [PubMed: 9867756]

10. Chen J, Normand SL, Wang Y, Drye EE, Schreiner GC, Krumholz HM. Recent declines in hospitalizations for acute myocardial infarction for Medicare fee-for-service beneficiaries: progress and continuing challenges. Circulation. 2010; 121(11):1322-1328. [PubMed: 20212281]

11. Mann D, Reynolds K, Smith D, Muntner P. Trends in statin use and low-density lipoprotein cholesterol levels among US adults: impact of the 2001 National Cholesterol Education Program guidelines. Ann Pharmacother. 2008; 42(9):1208-1215. [PubMed: 18648016]

12. Antman EM, Tanasijevic MJ, Thompson B, et al. Cardiac-specific troponin I levels to predict the risk of mortality in patients with acute coronary syndromes. N Engl J Med. 1996; 335(18):13421349. [PubMed: 8857017]

13. Urban P, Radovanovic D, Erne P, et al. AMIS Plus Investigators. Impact of changing definitions for myocardial infarction: a report from the AMIS registry. Am J Med. 2008; 121(12):1065-1071. [PubMed: 19028202]

14. Mills NL, Churchhouse AM, Lee KK, et al. Implementation of a sensitive troponin I assay and risk of recurrent myocardial infarction and death in patients with suspected acute coronary syndrome. JAMA. 2011; 305(12):1210-1216. [PubMed: 21427373]

15. Howard VJ, Cushman M, Pulley L, et al. The reasons for geographic and racial differences in stroke study: objectives and design. Neuroepidemiology. 2005; 25(3):135-143. [PubMed: 15990444]

16. Howard VJ, Woolson RF, Egan BM, et al. Prevalence of hypertension by duration and age at exposure to the stroke belt. J Am Soc Hypertens. 2010; 4(1):32-41. [PubMed: 20374949]

17. Luepker RV, Apple FS, Christenson RH, et al. AHA Council on Epidemiology and Prevention; AHA Statistics Committee; World Heart Federation Council on Epidemiology and Prevention; European Society of Cardiology Working Group on Epidemiology and Prevention; Centers for Disease Control and Prevention; National Heart, Lung, and Blood Institute. Case definitions for acute coronary heart disease in epidemiology and clinical research studies: a statement from the AHA Council on Epidemiology and Prevention; AHA Statistics Committee; World Heart 
Federation Council on Epidemiology and Prevention; the European Society of Cardiology Working Group on Epidemiology and Prevention; Centers for Disease Control and Prevention; and the National Heart, Lung, and Blood Institute. Circulation. 2003; 108(20):2543-2549. [PubMed: 14610011]

18. Thygesen K, Alpert JS, White HD, et al. Joint ESC/ACCF/AHA/WHF Task Force for the Redefinition of Myocardial Infarction. Universal definition of myocardial infarction. Circulation. 2007; 116(22):2634-2653. [PubMed: 17951284]

19. Prineas, RJ.; Crow, RS.; Blackburn, H. The Minnesota Code Manual of Electrocardiographic Findings: Standards and Procedures for Measurement and Classification. Boston, MA: WrightOSG; 1982.

20. Prineas, RJ.; Crow, RS.; Zhang, Z-M. Minnesota Code Manual of Electrocardiographic Findings. 2nd ed.. London, England: Springer-Verlag; 2010.

21. Tate, J.; Barth, J.; Bunk, D., et al. [Accessed March 20, 2012] Analytical characteristics of commercial and research cardiac troponin I and T assays declared by the manufacturer. 2012. http://www.ifcc.org/media/102202/ IFCC_Troponin_Table_vDec_2010_FINAL_ug_L_28Jan11.pdf

22. Epstein AJ, Polsky D, Yang F, Yang L, Groeneveld PW. Coronary revascularization trends in the United States, 2001-2008. JAMA. 2011; 305(17):1769-1776. [PubMed: 21540420]

23. Spertus JA, Salisbury AC, Jones PG, Conaway DG, Thompson RC. Predictors of quality-of-life benefit after percutaneous coronary intervention. Circulation. 2004; 110(25):3789-3794. [PubMed: 15596563]

24. Lin GA, Dudley RA, Lucas FL, Malenka DJ, Vittinghoff E, Redberg RF. Frequency of stress testing to document ischemia prior to elective percutaneous coronary intervention. JAMA. 2008; 300(15):1765-1773. [PubMed: 18854538]

25. Nallamothu BK, Rogers MA, Chernew ME, Krumholz HM, Eagle KA, Birkmeyer JD. Opening of specialty cardiac hospitals and use of coronary revascularization in medicare beneficiaries. JAMA. 2007; 297(9):962-968. [PubMed: 17341710]

26. Ross JS, Ho V, Wang Y, et al. Certificate of need regulation and cardiac catheterization appropriateness after acute myocardial infarction. Circulation. 2007; 115(8):1012-1019. [PubMed: 17283258]

27. Peterson ED, Shaw LK, DeLong ER, Pryor DB, Califf RM, Mark DB. Racial variation in the use of coronary-revascularization procedures: are the differences real? do they matter? N Engl J Med. 1997; 336(7):480-486. [PubMed: 9017942]

28. Hemingway H, Crook AM, Feder G, et al. Underuse of coronary revascularization procedures in patients considered appropriate candidates for revascularization. N Engl J Med. 2001; 344(9):645654. [PubMed: 11228280]

29. Jha AK, Fisher ES, Li Z, Orav EJ, Epstein AM. Racial trends in the use of major procedures among the elderly. N Engl J Med. 2005; 353(7):683-691. [PubMed: 16107621]

30. Lucas FL, DeLorenzo MA, Siewers AE, Wennberg DE. Temporal trends in the utilization of diagnostic testing and treatments for cardiovascular disease in the United States, 1993-2001. Circulation. 2006; 113(3):374-379. [PubMed: 16432068]

31. Levey AS, Stevens LA, Schmid CH, et al. CKD-EPI (Chronic Kidney Disease Epidemiology Collaboration). A new equation to estimate glomerular filtration rate. Ann Intern Med. 2009; 150(9):604-612. [PubMed: 19414839]

32. Rubin DB, Schenker N. Multiple imputation in health-care databases: an overview and some applications. Stat Med. 1991; 10(4):585-598. [PubMed: 2057657]

33. Rubin DB. Multiple imputation after 18+ years. J Am Stat Assoc. 1996; 91(434):473-489.

34. Jones DW, Chambless LE, Folsom AR, et al. Risk factors for coronary heart disease in African Americans: the atherosclerosis risk in communities study, 1987-1997. Arch Intern Med. 2002; 162(22):2565-2571. [PubMed: 12456228]

35. Soliman EZ, Prineas RJ, Case LD, et al. Electrocardiographic and clinical predictors separating atherosclerotic sudden cardiac death from incident coronary heart disease. Heart. 2011; 97(19): 1597-1601. [PubMed: 21775508] 
36. Thygesen K, Alpert JS, Jaffe AS, White HD. Diagnostic application of the universal definition of myocardial infarction in the intensive care unit. Curr Opin Crit Care. 2008; 14(5):543-548. [PubMed: 18787447]

37. Thygesen K, Alpert JS, White HD. Joint ESC/ACCF/AHA/WHF Task Force for the Redefinition of Myocardial Infarction. Universal definition of myocardial infarction. J Am Coll Cardiol. 2007; 50(22):2173-2195. [PubMed: 18036459]

38. Halim SA, Mulgund J, Chen AY, et al. Use of guidelines-recommended management and outcomes among women and men with low-level troponin elevation: insights from CRUSADE. Circ Cardiovasc Qual Outcomes. 2009; 2(3):199-206. [PubMed: 20031838]

39. Hochholzer W, Buettner HJ, Trenk D, et al. New definition of myocardial infarction: impact on long-term mortality. Am J Med. 2008; 121(5):399-405. [PubMed: 18456036]

40. Thygesen K, Alpert JS, Jaffe AS, et al. the Writing Group on behalf of the Joint ESC/ACCF/AHA/ WHF Task Force for the Universal Definition of Myocardial Infarction; Authors/Task Force Members Chairpersons; Biomarker Subcommittee; ECG Subcommittee; Imaging Subcommittee; Classification Subcommittee; Intervention Subcommittee; Trials \& Registries Subcommittee; Heart Failure Subcommittee; Epidemiology Subcommittee; Global Perspective Subcommittee; ESC Committee for Practice Guidelines (CPG); Document Reviewers. Third universal definition of myocardial infarction. Eur Heart J. 2012

41. Mills NL, Lee KK, McAllister DA, et al. Implications of lowering threshold of plasma troponin concentration in diagnosis of myocardial infarction: cohort study. BMJ. 2012 344e1533. 

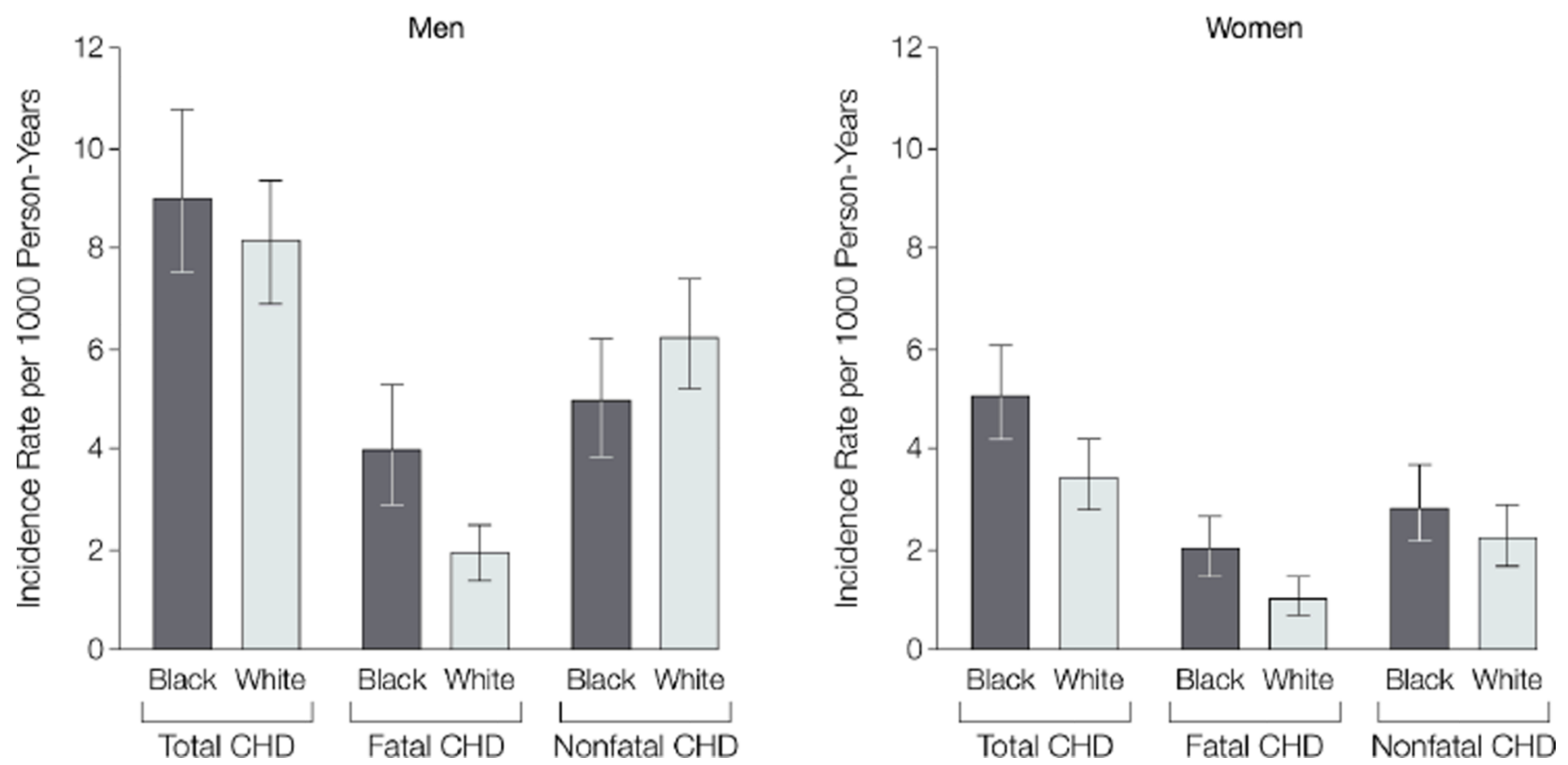

Figure.

Data are through December 31, 2009. Error bars indicate 95\% confidence intervals. The P values for the differences between black and white men are total $\mathrm{CHD}, \mathrm{P}=.30$; fatal $\mathrm{CHD}$, $\mathrm{P}<.001$; and nonfatal CHD, $\mathrm{P}=.07$. The $\mathrm{P}$ values for the differences between black and white women are total $\mathrm{CHD}, \mathrm{P}=.002$; fatal $\mathrm{CHD}, \mathrm{P}=.003$; and nonfatal $\mathrm{CHD}, \mathrm{P}=.10$. 


\section{Table 1}

Baseline Characteristics of REGARDS Cohort Members Without Coronary Heart Disease at Baseline.

\begin{tabular}{|c|c|c|c|c|}
\hline & \multicolumn{4}{|c|}{ No. (\%) of Cohort ${ }^{a}$} \\
\hline & \multicolumn{2}{|c|}{ Men } & \multicolumn{2}{|c|}{ Women } \\
\hline & $\begin{array}{c}\text { Black } \\
(\mathbf{n}=3739)\end{array}$ & $\begin{array}{c}\text { White } \\
(n=6420)\end{array}$ & $\begin{array}{c}\text { Black } \\
(\mathbf{n}=6609)\end{array}$ & $\begin{array}{c}\text { White } \\
(\mathbf{n}=7675)\end{array}$ \\
\hline \multicolumn{5}{|l|}{ Region } \\
\hline Stroke belt $b$ & $1245(33.3)$ & $2221(34.6)$ & $2252(34.1)$ & $2762(36.0)$ \\
\hline Stroke buckle ${ }^{c}$ & $604(16.2)$ & $1261(19.6)$ & $1272(19.2)$ & $1975(25.7)$ \\
\hline Non-stroke belt or buckle & $1890(50.5)$ & $2938(45.8)$ & 3085 (46.7) & $2938(38.3)$ \\
\hline Education $\leq$ high school & $685(18.3)$ & $380(5.9)$ & $1249(18.9)$ & $509(6.6)$ \\
\hline Annual income $<\$ 20000^{d}$ & $704(21.0)$ & $428(7.3)$ & $1951(34.3)$ & $1109(17.1)$ \\
\hline Antihypertensive medication use & $2080(57.7)$ & $2420(39.4)$ & $4216(66.3)$ & $3074(41.7)$ \\
\hline Diabetes & $1176(31.5)$ & $1110(17.3)$ & $2046(31.0)$ & 1119 (14.6) \\
\hline Statin use & $940(25.2)$ & $1823(28.5)$ & $1668(25.3)$ & $1892(24.7)$ \\
\hline Current smokere & $730(19.6)$ & $738(11.5)$ & $1012(15.4)$ & $973(12.7)$ \\
\hline \multirow{2}{*}{$\begin{array}{l}\text { Estimated glomerular filtration } \\
\text { rate }<60 \mathrm{~mL} / \mathrm{min}\end{array}$} & $355(10.0)$ & $499(8.0)$ & $666(10.7)$ & $686(9.3)$ \\
\hline & \multicolumn{4}{|c|}{ Mean (SD) } \\
\hline Age, y & $63.9(9.2)$ & $64.9(9.2)$ & $63.5(9.3)$ & $64.1(9.5)$ \\
\hline Body Mass Index $f$ & $28.9(5.4)$ & $28.2(4.8)$ & $31.9(7.1)$ & $28.2(6.2)$ \\
\hline \multicolumn{5}{|l|}{ Cholesterol, mg/dL } \\
\hline Total & $187.0(39.5)$ & $187.2(36.4)$ & $198.8(40.5)$ & $202.7(38.5)$ \\
\hline High-density lipoprotein & $48.4(14.6)$ & $44.9(13.3)$ & $57.2(15.9)$ & $57.9(16.4)$ \\
\hline \multirow[t]{2}{*}{ Systolic blood pressure, $\mathrm{mm} \mathrm{Hg}$} & $131.7(16.9)$ & $126.8(15.0)$ & $129.5(17.2)$ & $123.0(15.7)$ \\
\hline & \multicolumn{4}{|c|}{ Median $\left(25^{\text {th }}-75^{\text {th }}\right)$} \\
\hline $\begin{array}{l}\text { High-sensitivity C-reactive } \\
\text { protein, } \mathrm{mg} / \mathrm{L}\end{array}$ & $2.0(0.92-4.4)$ & $1.5(0.7-3.3)$ & $3.5(1.4-7.5)$ & $2.2(1.0-4.9)$ \\
\hline $\begin{array}{l}\text { Ratio of albumin to creatinine, } \\
\mathrm{mg} / \mathrm{g}\end{array}$ & $7.2(4.1-20.9)$ & $5.9(4.0-12.0)$ & $7.7(4.9-17.0)$ & $7.5(5.0-13.1)$ \\
\hline
\end{tabular}

Abbreviation: REGARDS, Reasons for Geographic and Racial Differences in Stroke.

SI conversion factors: To convert C-reactive protein to $\mathrm{nmol} / \mathrm{L}$, multiply by 9.524 ; high-density lipoprotein and total cholesterol to $\mathrm{mmol} / \mathrm{L}$, multiply by 0.0259 .

${ }^{a}$ Unless otherwise indicated.

$b$ Defined as the states of Alabama, Arkansas, Louisiana, Mississippi, Tennessee and the noncoastal regions within the states of North Carolina, South Carolina, and Georgia.

${ }^{c}$ Defined as the coastal regions within the states of North Carolina, South Carolina, and Georgia.

$d_{\text {The }} 3033$ (12.4\%) who declined to report income were not included in the denominator.

e Defined as having smoked at least 100 cigarettes in one's lifetime and currently smoking, even if only occasionally.

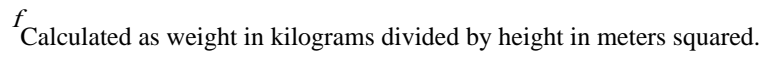

JAMA. Author manuscript; available in PMC 2013 September 13. 


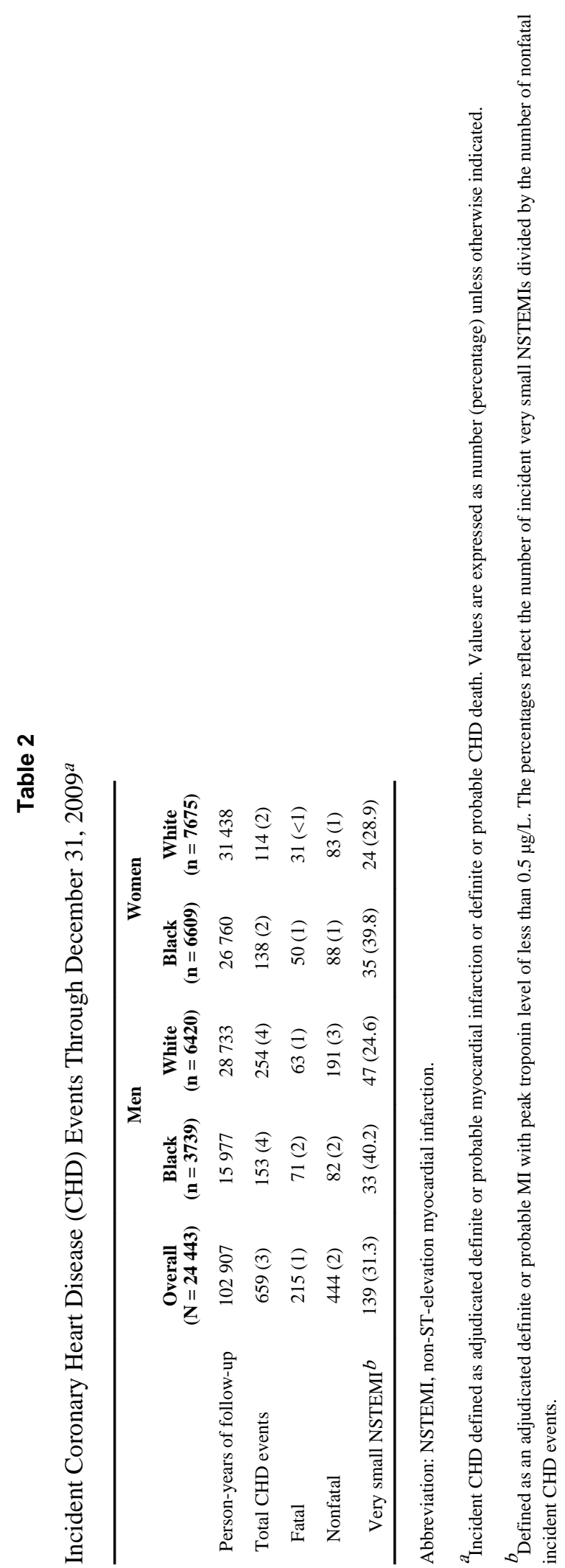

JAMA. Author manuscript; available in PMC 2013 September 13. 
Table 3

Total, Fatal, and Nonfatal Acute Coronary Heart Disease (CHD) Events.

\begin{tabular}{|c|c|c|c|}
\hline & \multicolumn{2}{|c|}{ Black vs White, Hazard Ratio (95\% CI) } & \\
\hline & Men & Women & \\
\hline \multicolumn{4}{|l|}{ Total CHD } \\
\hline Model $1^{a}$ & $1.15(0.94-1.41)$ & $1.48(1.15-1.90)$ & \\
\hline Model $2^{b}$ & $1.04(0.84-1.29)$ & $1.25(0.96-1.62)$ & \\
\hline Model $3^{c}$ & $0.93(0.74-1.16)$ & $0.95(0.72-1.25)$ & \\
\hline Model $4^{d}$ & $0.87(0.69-1.08)$ & $0.90(0.68-1.20)$ & \\
\hline \multicolumn{4}{|l|}{ Fatal CHD } \\
\hline Model $1^{a}$ & $2.18(1.55-3.06)$ & $1.93(1.23-3.03)$ & \\
\hline Model $2^{b}$ & $1.78(1.24-2.56)$ & $1.63(1.02-2.62)$ & \\
\hline Model $3^{c}$ & $1.50(1.02-2.19)$ & $1.20(0.73-1.97)$ & \\
\hline Model $4^{d}$ & $1.34(0.91-1.96)$ & $1.14(0.69-1.99)$ & \\
\hline \multicolumn{4}{|c|}{ Non-fatal CHD } \\
\hline Model $1^{a}$ & $0.81(0.63-1.06)$ & $1.31(0.97-1.77)$ & \\
\hline Model $2^{b}$ & $0.78(0.60-1.03)$ & $1.10(0.80-1.52)$ & \\
\hline Model $3^{c}$ & $0.72(0.54-0.95)$ & $0.85(0.61-1.19)$ & \\
\hline Model $4^{d}$ & $0.68(0.51-0.91)$ & $0.81(0.58-1.15)$ & \\
\hline \multicolumn{4}{|c|}{ Adjusted for age and region of residence. } \\
\hline \multicolumn{4}{|c|}{ Adjusted for model 1 covariates plus education level and income. } \\
\hline
\end{tabular}


Table 4

Nonfatal Myocardial Infarctions (MIs) by Typical and Very Small Non-St-Elevation MI (NSTEMI) Classification $^{a}$

\begin{tabular}{lcc}
\hline & \multicolumn{2}{c}{ Black vs White, Hazard Ratio $(95 \%$ CI) } \\
Men & Women \\
Nonfatal typical MI & & \\
Model $1^{b}$ & $0.65(0.47-0.89)$ & $1.11(0.76-1.61)$ \\
Model $^{c}$ & $0.64(0.45-0.90)$ & $0.97(0.65-1.44)$ \\
Model $3^{d}$ & $0.64(0.45-0.91)$ & $0.75(0.50-1.14)$ \\
Model $4^{e}$ & $0.62(0.44-0.88)$ & $0.74(0.49-1.14)$ \\
Nonfatal very small NSTEMI & & \\
Model $1^{b}$ & $1.33(0.85-2.09)$ & $1.79(1.06-3.03)$ \\
Model $2^{c}$ & $1.22(0.76-1.95)$ & $1.44(0.83-2.51)$ \\
Model $3^{d}$ & $0.93(0.57-1.52)$ & $1.08(0.60-1.92)$ \\
Model $4^{e}$ & $0.83(0.50-1.37)$ & $0.97(0.54-1.74)$ \\
\hline
\end{tabular}

${ }^{a}$ Very small NSTEMI defined as a nonfatal incident CHD event with highest troponin level of less than $0.50 \mu \mathrm{g} / \mathrm{L}$.

${ }^{b}$ Adjusted for age and region of residence.

${ }^{c}$ Adjusted for model 1 covariates, education level, and income.

${ }^{d}$ Adjusted for model 2 covariates, total cholesterol, high-density lipoprotein cholesterol, smoking status, systolic blood pressure, diabetes, and use of antihypertensive and statin medications.

${ }^{e}$ Adjusted for model 3 covariates, body mass index, estimated glomerular filtration rate of less than $60 \mathrm{~mL} / \mathrm{min}$, log-transformed high-sensitivity Creactive protein, and log-transformed albumin-to-creatinine ratio. 